\title{
On Being New to an Insurance Plan: Health Care Use Associated With the First Years in a Health Insurance Plan
}

Peter Franks, MD

Colin Cameron, $\mathrm{PbD}$

Klea D. Bertakis, MD

Center for Health Services Research in Primary Care and Department of Family and Community Medicine, University of California, Davis, Calif
Conflict of interest: none reported

\section{CORRESPONDING AUTHOR}

Peter Franks, MD

Center for Health Services Research in Primary Care, Department of Family and Community Medicine, University of California, Davis

4860 Y Street, Ste 2300

Sacramento, CA 95817

pfranks@ucdavis.edu

\begin{abstract}
BACKGROUND We wanted to compare health care utilization and costs in the first year of being in a health insurance plan with those of subsequent years.

METHODS We used claims data from an independent practitioner association (IPA)-style managed care organization in the Rochester, NY, metropolitan area from 1996 through 1999. Cross-sectional and panel analyses of up to 4 years of claims data were conducted, involving 335,547 adult patients assigned to the panels of 687 primary care physicians (internists and family physicians). Multivariate analyses, adjusting for age, sex, case mix, and socioeconomic status derived from ZIP codes, examined the relationship between the first year of health insurance and Papanicolaou tests, mammograms in women older than 40 years, physician use, avoidable hospitalization, and expenditures.
\end{abstract}

RESULTS After multivariate adjustment, the first year of insurance was associated with a higher risk of not getting a mammogram, a higher risk of avoidable hospitalization, greater likelihood of visiting a physician, and higher expenditures, especially for testing. There was no relationship, however, between Papanicolaou test compliance and year of enrollment.

CONCLuSIONS The findings suggest there might be adverse clinical and financial implications associated with changing insurance.

Ann Fam Med 2003;1:156-161. DOI: 10.1370/afm.24.

\section{INTRODUCTION}

$\mathrm{R}$ ecent economic pressures in the health insurance market have resulted in cycles of increased costs, reduced benefits, and consumer dissatisfaction. Consequent to these pressures are disenrollment and more frequent changes in health insurance. ${ }^{1,2}$ Data from a 1996-1997 national survey suggests that $17 \%$ of privately insured persons changed their health plan in the year before the survey, most of them involuntarily. ${ }^{3}$ Forced discontinuity associated with health plan changes is associated with reduced levels of patient satisfaction. ${ }^{4}$ There has also been anecdotal concern that changes in health insurance might disrupt care and adversely affect outcomes. Little systematic information exists, however, about the consequences of these changes.

Disenrollment can result in loss of continuity with a health care provider and consequent patient-perceived loss of quality of primary care. ${ }^{1}$ Literature about the effects of continuity is limited., , $5-9^{-9}$ Mostly observational studies suggest that continuity is associated with increased satisfaction. ${ }^{10,11}$ Continuity is also associated with a lower risk of hospitalization and emergency department use. ${ }^{12-14}$ Continuity might be associated with improved health behaviors and prevention compliance. ${ }^{15-18}$ There is some circularity in these observational studies, in that patients who prefer conti- 
nuity might also be more compliant and satisfied with a long-term relationship with a provider. Forrest et al ${ }^{19}$ found that patients in a point-of-service plan who selfreferred to a specialist had less continuity, preferred direct access, and reported problems with their primary care physician. Relatively few other studies, mostly dating from the 1970s, address the possible costs of continuity. ${ }^{20-23}$ From a physician's perspective, increased continuity is associated with greater knowledge about patients, resulting in shorter consultations and less laboratory testing. ${ }^{24}$ In the only recent randomized trial of the effects of continuity, Wasson et $\mathrm{al}^{25}$ found that male veterans older than 55 years assigned to a continuity group had fewer emergency hospitalizations, shorter hospitalizations, and greater satisfaction than men in a discontinuity group.

The extent to which studies on continuity apply to discontinuity in health insurance is unknown. There are few systematic studies of the effects of insurance change. Some evidence suggests that patients delay follow-up from emergency department visits after changing, and particularly after losing, health insurance. ${ }^{26}$

As an approach to assessing the possible impact of changing insurance, we compared health care indicators for persons newly enrolled in a health plan with those in subsequent years of being insured in the same health plan. Health care indicators selected were those that could be reliably identified in a claims database. Based on the continuity literature, we hypothesized that persons in their first year would be less likely to be in compliance with preventive procedures and generate higher expenditures as a result of increased laboratory testing. We also hypothesized that persons in their first year in the health plan would have a higher risk of avoidable hospitalization, because they might have had less opportunity to obtain timely ambulatory care.

\section{METHODS}

The investigation was conducted in the 10-county area around Rochester, NY, using the claims database of the largest local managed care organization. At the time of the study, more than $50 \%$ of the local population was enrolled in this organization. Its structure is based on an independent practitioner association model in which neither primary care physicians nor specialists are capitated. Each patient is assigned to a primary care physician, and more than $95 \%$ of local primary care physicians participate in the independent practice association. The patient study sample comprised adults, 21 to 64 years of age, who were assigned to a primary care physician (687 family physicians and internists) during any of the 4 years from 1996 to 1999 . Female enrollees may also select an obstetrician-gynecologist as an addi- tional primary care physician. To facilitate comparisons between family physicians and internists, and because it is possible to enroll in health insurance plans specifically for planned pregnancy care, visits for obstetric care were excluded. We also excluded data on persons (28\%) enrolled for less than 363 days during the year.

\section{Variables}

All variables were derived from the claims data: age, sex, avoidable hospitalization during the year, expenditures during the year, case mix, socioeconomic status derived from patient ZIP codes, and years of enrollment. Women were coded according to whether they had a Papanicolaou test each year, and women older than 40 years were coded according to whether they had a mammogram. All patients were coded according to whether they had any physician visit and whether they had a visit to their primary care physician. The first year of enrollment was defined as the first full year the patient appeared in the data set, excluding the first year of available data (1996, because no reliable flag was available in the data set to indicate whether the patient had been enrolled the previous year). Other variables are defined below.

Avoidable Hospitalization Conditions. We used Weissman and Epstein's approach ${ }^{27}$ to classify hospitalizations as avoidable or not avoidable. Based on previous research, ${ }^{27-29} 6$ medical conditions meet the criteria for avoidable hospitalization conditions that might benefit from timely specialist care: angina, congestive heart failure, hypertension, asthma, chronic obstructive pulmonary disease, and diabetes mellitus. Patients were classified according to whether they were admitted during each of the 4 years for any of the avoidable hospitalization conditions.

Expenditures. Total expenditures per panel member per year for each member were calculated from the "allowed amount" variable in the claims files. The allowed amount is the sum of the amount paid, the copayment, deductible, and amount withheld for the risk pool. The allowed amounts varied across providers, so we standardized prices using the claims data. We also standardized prices for all years to 1996 prices. For physician claims, the standardized prices were the average amounts allowed for each current procedural terminology (CPT-4) ${ }^{30}$ code and provider specialty. For inpatient hospital claims, the standardized price was the average of allowed amounts by diagnosis-related group. For all other claims, the standardized price was the average of amounts allowed by CPT- 4 code, with separate facility and nonfacility categories. Total expenditures for each patient were defined as the sum of the standardized prices for all services listed on the patient's claim for the calendar year. In addition to total 
expenditures, we separated expenditures for inpatient hospital claims, physician encounter claims, and diagnostic testing.

Socioeconomic Status. A summary socioeconomic status indicator was derived for each patient based on 1990 census socioeconomic indicators for the patient's ZIP code (215 ZIP codes represented). We have previously found, as have others, that measures of socioeconomic status based on ZIP codes are as useful indicators of the health-related effects of socioeconomic status as are smaller areas, such as block groups or individual measures. ${ }^{31,32}$ The indicators chosen were median household income, percentage white, percentage with at least a high school graduation level of education, and percentage white-collar workers. We used principal components analysis ${ }^{33}$ to derive a single socioeconomic status factor explaining as much as possible of the variance in the indicators.

Case Mix. Case-mix adjustment was based on the ambulatory care groups (ACG) system. ${ }^{34}$ We used the ambulatory diagnostic groups (ADGs) of the ACG system because we have found, ${ }^{35}$ as have Salem-Schatz et $\mathrm{al}_{1}{ }^{36}$ that $\mathrm{ADG}$ explained more of the variation in resource use than the ACG indicators. Based on the diagnoses in the claims data accumulated by the patient each year, a dummy indicator was derived for each ADG.

\section{Analyses}

The analyses were conducted at the level of the patient. To account for the nesting of patients within year and within physician, the analyses were conducted using the generalized estimating equations approach, ${ }^{37}$ and an exchangeable working correlation structure for the nested observations was implemented using SUDAAN. ${ }^{38}$ All analyses were adjusted for patient age (mean age minus age), age squared, sex, and ZIP-code-derived socioeconomic status. In addition, case-mix adjustment was used for analyses of avoidable hospitalization risk and expenditures. Year of enrollment (1 through 4 ) was included as a series of dummy variables, with year 4 as the reference year. Analyses were conducted with and without adjustment for year (1997 through 1999), which exhibited some collinearity with year of enrollment. The results were broadly similar, and reported results include adjustment for year. Logistic regression analyses were used for Papanicolaou testing, mammogram testing, avoidable hospitalization, any primary care physician visit, and any physician visit.

To better reflect the effect sizes of the associations of being newly insured with the dependent variables, the odds ratios obtained from the logistic regression analyses were transformed to relative risks, using the method of Zhang and Yu. ${ }^{39}$ Expenditures were trans- formed using logarithms to normalize their distributions and analyzed with ordinary linear regression. Retransformed results are reported as percent changes in costs associated with being newly insured compared with being insured for at least 4 years. The large number of covariates involved in analyses using the ADG case-mix adjustment, together with the large number of observations, precluded analyzing the entire data set. Thus, for analyses involving adjustment for ADGs, only 1 year of a possible 4 that each patient was enrolled was randomly selected once only for inclusion in the analysis.

\section{RESULTS}

Between 1997 and 1999, an average of $22.8 \%$ of patients were enrolled each year. Between 1996 and 1998 , an average of $19.6 \%$ of patients were disenrolled each year. The profile of persons $(5.5 \%)$ enrolled for 1 year only (1997 or 1998) looked similar to those enrolled in their first year (data not shown). Those in their first year of enrollment compared with those in later years of enrollment were slightly younger, more likely to be female, to have a lower level of socioeconomic status, and to have slightly fewer accumulated ADGs (Table 1, all differences significant, reflecting the large sample size). Those enrolled in their first year were also more likely to have any visit and a visit with their primary care provider, less likely to have a Papanicolaou test or a mammogram, but more likely to have an avoidable hospitalization (Table 1). Avoidable hospitalizations were rare, occurring in $0.16 \%$ of patients and making up $3.3 \%$ of all hospitalizations.

The adjusted results for the prevention measures are shown in Table 2. There was no significant relationship between year of enrollment and the likelihood of receiving a Papanicolaou test. Women older than 40 years in their first year of enrollment, however, were $13 \%$ less likely to obtain a mammogram when compared with women in their fourth year. The effects for the second and third years were progressively smaller. Table 2 also shows that after adjustment the risk of an avoidable hospitalization was $89 \%$ higher than the fourth year. A smaller, but statistically significant, effect was also noted for the second year.

Table 3 shows the adjusted results for expenditures. Total, testing, and ambulatory expenditures were higher in the first year, with the effects most marked for testing. There was no significant relationship between inpatient expenditures and year of enrollment.

\section{DISCUSSION}

The $20 \%$ annual turnover in insurance observed in this study represents a considerable proportion of those 


\begin{tabular}{|c|c|c|c|c|}
\hline Variable & $\begin{array}{l}\text { First Year } \\
\text { No. (SD) }\end{array}$ & $\begin{array}{l}\text { Second Year } \\
\text { No. (SD) }\end{array}$ & $\begin{array}{l}\text { Third Year } \\
\text { No. (SD) }\end{array}$ & $\begin{array}{l}\text { Fourth Year } \\
\text { No. (SD) }\end{array}$ \\
\hline Number of patients & 31,994 & 127,976 & 94,854 & 80,723 \\
\hline Age, years & $40.8(10.9)$ & $43.1(10.9)$ & $44.7(10.6)$ & $45.8(10.0)$ \\
\hline Female, \% & 53.5 & 52.5 & 51.5 & 51.0 \\
\hline ZIP, socioeconomic status & $0.03(1.00)$ & $0.03(0.98)$ & $0.05(0.98)$ & $0.07(0.98)$ \\
\hline ZIP, > 12 years school, $\%$ & $63.9(7.80)$ & $64.3(7.61)$ & $64.5(7.6)$ & $64.6(7.6)$ \\
\hline ZIP, median household income, $\$$ & $37,002(10,228)$ & $37,728(10,176)$ & $37,905(10,189)$ & $38,194(10,317)$ \\
\hline ZIP, white, \% & $93.9(12.0)$ & $94.4(11.2)$ & $94.5(10.9)$ & $94.7(10.7)$ \\
\hline ZIP, white-collar work, \% & $74.2(8.53)$ & $74.4(8.6)$ & $74.6(8.6)$ & $74.8(8.7)$ \\
\hline Total years enrolled & $1.27(0.56)$ & $2.73(0.82)$ & $3.49(0.50)$ & $4.0(0)$ \\
\hline Total ambulatory diagnostic groups & $3.5(2.68)$ & $3.3(2.75)$ & $3.5(2.82)$ & $3.7(2.90)$ \\
\hline Any visit, \% & 90.1 & 86.2 & 87.0 & 88.5 \\
\hline Any primary care provider visit & 55.6 & 49.2 & 50.0 & 49.6 \\
\hline Mammogram & 51.0 & 52.3 & 56.8 & 58.8 \\
\hline Papanicolaou test & 59.5 & 61.1 & 60.1 & 60.5 \\
\hline Avoidable hospitalization, \% & 0.18 & 0.15 & 0.12 & 0.15 \\
\hline Expenditures (including nonusers), \$ & Mean/Median & Mean/Median & Mean/Median & Mean/Median \\
\hline Total & $1,086 / 313$ & $1,035 / 285$ & $1,112 / 317$ & $1,250 / 359$ \\
\hline Diagnostic & $224 / 41$ & $230 / 43$ & $245 / 46$ & $221 / 11$ \\
\hline Ambulatory & $281 / 134$ & $282 / 127$ & $297 / 137$ & $332 / 160$ \\
\hline Inpatient & $280 / 0$ & $258 / 0$ & $259 / 0$ & $307 / 0$ \\
\hline \multicolumn{5}{|l|}{ Expenditures (contingent on use), \$ } \\
\hline Total & $1,223 / 383$ & $1,227 / 387$ & $1,306 / 428$ & $1,440 / 467$ \\
\hline Diagnostic & $354 / 137$ & $369 / 165$ & $392 / 165$ & $399 / 131$ \\
\hline Ambulatory & $347 / 183$ & $366 / 189$ & $379 / 203$ & $409 / 217$ \\
\hline Inpatient & $5,751 / 3,005$ & $5,617 / 2,950$ & $5,698 / 2,902$ & $6,244 / 3,019$ \\
\hline
\end{tabular}

insured and is consistent with previous national data. ${ }^{3}$ Our findings of reduced prevention, at least for mammograms, and increased testing expenditures among the newly insured are consistent with our hypotheses and the limited continuity literature. ${ }^{15,16,24}$ These previous studies examined immunization status in children in a continuity clinic, ${ }^{15}$ recall by Norwegian general practitioners about their testing behavior with patients with more or less continuity, ${ }^{24}$ and self-report on prevention by respondents with and without a usual source of care. ${ }^{16}$ We have also found modest beneficial associations between self-reported continuity and prevention in the 1996-1997 nationally representative Community Tracking Survey. ${ }^{40}$

The absence of effect for Papanicolaou tests contrasts with the effect for mammograms. It might be that Papanicolaou tests are a more established part of women's health care, a routine that they carry with them from one insurance status (or no insurance) to the next more easily than getting mammograms. Mammograms might require more encouragement from physicians and the managed care organization, encouragement that requires some time to yield benefits.

Consistent with our hypothesis, avoidable hospital- izations were associated with being new to the insurance plan. The results are also congruent with the observations of Burstin et al, ${ }^{26}$ who found newly insured persons delayed follow-up after emergency department visits. Because avoidable hospitalizations are relatively rare events, they might be of limited use in monitoring the possible adverse effects of being in a new health insurance plan. Although avoidable hospitalizations have been proposed to be included in Health Plan Employer Data and Information Set as a measure to assess quality of care, there is controversy about its validity. ${ }^{41}$

The higher adjusted expenditures in newly insured patients might reflect either decreased efficiency of care delivery or appropriate catch-up in care, especially for those without previous health insurance. Because we could not distinguish between persons switching health plans and those not previously insured, we were unable to develop a reliable algorithm for the claims data that would allow distinction between these two possibilities. More detailed analyses, including primary data collection, are required to assess these hypotheses. The net effects per enrollee are probably underestimated, because the analyses included only those with 


\begin{tabular}{|c|c|c|c|}
\hline Variable & $\begin{array}{c}\text { First Year } \\
\text { RR }(95 \% \mathrm{Cl})\end{array}$ & $\begin{array}{l}\text { Second Year } \\
\text { RR ( } 95 \% \mathrm{Cl})\end{array}$ & $\begin{array}{l}\text { Third Year } \\
\text { RR (95\% Cl) }\end{array}$ \\
\hline Any visit & $1.02(1.02,1.03)$ & $0.98(0.98,0.99)$ & $0.99(0.99,0.99)$ \\
\hline $\begin{array}{l}\text { Any primary care } \\
\text { provider visit }\end{array}$ & $1.15(1.15,1.14)$ & $1.03(1.02,1.04)$ & $1.00(0.99,1.01)$ \\
\hline Mammogram & $0.87(0.87,0.88)$ & $0.89(0.88,0.90)$ & $0.97(0.96,0.97)$ \\
\hline Papanicolaou test & $0.99(0.98,1.00)$ & $1.02(1.01,1.02)$ & $1.00(0.99,1.00)$ \\
\hline $\begin{array}{l}\text { Avoidable } \\
\text { hospitalization }\end{array}$ & $1.89(1.26,2.81)$ & $1.68(1.10,2.55)$ & $1.00(0.62,1.62)$ \\
\hline \multicolumn{4}{|c|}{$\mathrm{RR}=$ relative risk, $\mathrm{Cl}=$ confidence interval. } \\
\hline \multicolumn{4}{|c|}{$\begin{array}{l}\text { Note: Each row represents a separate logistic regression. Shown are the adjusted relative risks (and } 95 \% \\
\text { confidence intervals) associated with each year of enrollment, with the fourth year the reference year. These } \\
\text { analyses adjust for patient age, sex, socioeconomic status, and year. The avoidable hospitalization analysis } \\
\text { adjusted for case mix as well. For the mammogram analysis, number of observations }=243,614 ; \text { for the } \\
\text { Papanicolaou analysis, } N=417,210 \text {; and for the any visit and any primary care provider visit analyses, } \\
N=798,967 \text {. In these } 4 \text { analyses individual patients may be included for each year they were enrolled. } \\
\text { For the avoidable hospitalization analysis, each patient was included only once, } N=335,547 \text {. }\end{array}$} \\
\hline
\end{tabular}

\section{Table 3. Adjusted Expenditures Contingent} on Use by Year of Enrollment

\begin{tabular}{lccc}
\hline $\begin{array}{l}\text { Expenditure } \\
\text { Category }\end{array}$ & $\begin{array}{c}\text { First Year } \\
\text { AMC (95\% Cl) }\end{array}$ & $\begin{array}{c}\text { Second Year } \\
\text { AMC (95\% Cl) }\end{array}$ & $\begin{array}{c}\text { Third Year } \\
\text { AMC (95\% CI) }\end{array}$ \\
Total & $1.05(1.03-1.07)$ & $1.02(1.00-1.04)$ & $1.03(1.01-1.05)$ \\
Diagnostic testing & $1.15(1.13-1.17)$ & $1.12(1.09-1.14)$ & $1.25(1.22-1.27)$ \\
Ambulatory care & $1.04(1.02-1.06)$ & $1.04(1.02-1.06)$ & $1.01(0.99-1.03)$ \\
Inpatient care & $1.03(0.93-1.14)$ & $0.99(0.88-1.11)$ & $0.99(0.88-1.11)$ \\
\hline
\end{tabular}

$\mathrm{AMC}=$ adjusted mean costs, $\mathrm{Cl}=$ confidence interval.

Note: Each row represents a separate linear regression. Shown are the adjusted mean costs and $95 \%$ confidence intervals associated with each year of enrollment relative to the fourth year. These analyses adjust for patient age, sex, socioeconomic status, ambulatory diagnostic groups, and year. For all analyses, $\mathrm{N}=335,547 ; 1$ observation per patient.

ble that other unmeasured confounders could explain the results.

Third, the findings could have the questionable generalizability. At the time of the study, the Rochester area was dominated by 2 managed care organizations, with very little penetration of the market by for-profit managed care organizations. There might be relatively little disruption in continuity, because many providers were involved in both managed care organizations.

Finally, a limited array of prevention measures and the only one indirect indicator of chronic disease management (avoidable hospitalization) were examined. It is plausible that disruption of care for chronic disease has the most profound adverse effect on health care. ${ }^{42}$

Despite these limitations, this study represents a step toward examining possible costs of changing insurance status. Depending on the measure examined, we observed adverse effects (less prevention, higher costs, more avoidable hospitalizations) that lasted up to 3 years from enrollment in the health plan. These findings are consistent with the observations of Hjortdahl that it took 1 to 5 years for the primary care physician's sense of medical

some expenditures, and newly enrolled persons were also more likely to visit a physician and generate at least some expenditures. In addition, waiting periods for patients new to the insurance plan are likely to result in some deferred care.

This study has a number of limitations. First, while the use of these claims data reduce biases associated with self-report, they do not allow separation of those who are previously uninsured from those previously insured with a different health plan. Thus, for persons facing forced discontinuity as a result of changes in insurance coverage, one might expect the adverse effects to be reflected in unnecessary additional evaluations as patient and physician get to know each other. For persons newly acquiring insurance, the increased utilization might be appropriate and reflect catch-up care and investigations.

Second, we found significant sociodemographic and clinical differences between those enrolled in their first year compared with those enrolled in subsequent years. Although we adjusted for these differences, it is possi- responsibility for and knowledge about their patients to reach adequate levels also reflected in resource use. ${ }^{24,43}$ Together with studies showing decreased patient satisfaction with forced health plan switches ${ }_{1}^{4}$ the findings suggest that there are likely pervasive adverse consequences of the frequent rebidding of insurance contracts by employers. Given the relative stability of the health care insurance market in Rochester, it is likely that these findings represent an underestimate of possible effects in more competitive insurance environments with more frequent insurance changes. Further analyses in these other settings are needed.

To read commentaries or to post a response to this article, see the online version at http://annfammed/cgi/content/full/1/3/156.

Acknowledgment This work was supported by a grant from the Agency for Healthcare Research and Quality, RO1 HS09963-01A1.

Key words: Managed care programs/utilization; insurance; preventive health services; health care costs; continuity of patient care

Submitted September 11, 2002; submitted, revised, December 9, 2002; accepted December 20, 2002. 


\section{References}

1. Flocke SA, Stange KC, Zyzanski SJ. The impact of insurance type and forced discontinuity on the delivery of primary care. J Fam Pract 1997;45:129-135.

2. Donaldson MS. Continuity of care: a reconceptualization. Med Care Res Rev 2001;58:255-290.

3. Cunningham PJ, Kohn L. Health plan switching: choice or circumstance? Health Aff (Millwood) 2000;19:158-164.

4. Davis, K. Schoen, C. Managed care, choice, and patient satisfaction. Available at http://www.cmwf.org/programs/health_care/ satis.asp. Accessed on December 5, 2002.

5. Dietrich AJ, Marton KI. Does continuous care from a physician make a difference? J Fam Pract 1982;15:929-937.

6. Freeman G, Hjortdahl P. What future for continuity of care in general practice? BMJ 1997;314:1870-1873.

7. Starfield B. Primary care: balancing health needs, services, and technology. New York: Oxford University Press; 1998.

8. Guthrie B, Wyke S, Brampton S. Controversy in primary care: Does continuity in general practice really matter? Commentary: A patient's perspective of continuity. BMJ 2000;321:734-736.

9. Christakis DA. Does continuity of care matter? Yes: consistent contact with a physician improves outcomes. West J Med 2001;175:4.

10. Hjortdahl P, Laerum E. Continuity of care in general practice: effect on patient satisfaction. BMJ 1992;304:1287-1290.

11. Doescher MP, Saver BG, Franks P, Fiscella K. Racial and ethnic disparities in perceptions of physician style and trust. Arch Fam Med 2000; 9:1156-1163.

12. Gill JM, Mainous AG III. The role of provider continuity in preventing hospitalizations. Arch Fam Med 1998;7:352-357.

13. Gill JM, Mainous AG III, Nsereko M. The effect of continuity of care on emergency department use. Arch Fam Med 2000;9:333-338.

14. Christakis DA, Mell L, Koepsell TD, Zimmerman FJ, Connell FA. Association of lower continuity of care with greater risk of emergency department use and hospitalization in children. Pediatrics 2001; 107:524-529.

15. Minkovitz CS, Belote AD, Higman SM, Serwint JR, Weiner JP. Effectiveness of a practice-based intervention to increase vaccination rates and reduce missed opportunities. Arch Pediatr Adolesc Med 2001; 155:382-386.

16. Ettner SL. The timing of preventive services for women and children: the effect of having a usual source of care. Am J Public Health 1996;86:1748-1754.

17. Ettner SL. The relationship between continuity of care and the health behaviors of patients: does having a usual physician make a difference? Med Care 1999;37:547-555.

18. Christakis DA, Mell L, Wright JA, Davis R, Connell FA. The association between greater continuity of care and timely measles- mumpsrubella vaccination. Am J Public Health 2000;90:962-965.

19. Forrest CB, Weiner JP, Fowles J, Vogeli $C$, et al. Self-referral in pointof-service health plans. JAMA 2001;285:2223-2231.

20. Miller MH. Who receives optimal medical care? J Health Soc Behav 1973; 14:176-182.

21. Morehead MA, Donaldson R. Quality of clinical management of disease in comprehensive neighborhood health centers. Med Care $1974 ; 12: 301-315$
22. Roos LL, Roos NP, Gilbert P, Nicol JP. Continuity of care: does it contribute to quality of care? Med Care 1980;18:174-184.

23. Wachter RM. Does continuity of care matter? No: discontinuity can improve patient care. West J Med 2001;175:5.

24. Hjortdahl P, Borchgrevink CF. Continuity of care: influence of general practitioners' knowledge about their patients on use of resources in consultations. BMJ 1991;303:1181-1184.

25. Wasson JH, Sauvigne AE, Mogielnicki RP, et al. Continuity of outpatient medical care in elderly men. A randomized trial. JAMA 1984;252:2413-2417.

26. Burstin HR, Swartz K, O'Neil AC, Orav EJ, Brennan TA. The effect of change of health insurance on access to care. Inquiry 1998;35:389397.

27. Weissman JS, Gatsonis C, Epstein AM. Rates of avoidable hospitalization by insurance status in Massachusetts and Maryland. JAMA 1992;268:2388-2394.

28. Parchman ML, Culler S. Primary care physicians and avoidable hospitalizations. J Fam Pract 1994;39:123-128.

29. Bindman $A B$, Grumbach $K$, Osmond $D$, et al. Preventable hospitalizations and access to health care. JAMA 1995;274:305-311.

30. Cpt 2003: Current procedural terminology (Cpt Standard Edition, 2003). 4th ed. Chicago: American Medical Association; 2002.

31. Geronimus AT, Bound J. Use of Census-based aggregate variables to proxy for socioeconomic group: evidence from national samples. Am J Epidemiol 1998;148:475-486.

32. Fiscella K, Franks P. Impact of patient socioeconomic status on physician profiles: a comparison of census-derived and individual measures. Med Care 2001;39:8-14.

33. Fisher LD, Van Belle G. Biostatistics. A methodology for the health sciences. New York: Wiley-Interscience; 1993

34. Weiner JP, Starfield BH, Steinwachs DM, Mumford LM. Development and application of a population-oriented measure of ambulatory care case-mix. Med Care 1991;29:452-472.

35. Franks $P$, Mooney $C$, Sorbero M. Physician referral rates: style without much substance? Med Care 2000;38:836-846.

36. Salem-Schatz S, Moore G, Rucker M, Pearson SD. The case for casemix adjustment in practice profiling. When good apples look bad. JAMA 1994;272:871-874

37. Zeger SL, Liang KY, Albert PS. Models for longitudinal data: a generalized estimating equation approach. Biometrics 1988;44:1049-1060

38. Research Triangle Institute. SUDAAN. Professional software for Survey DAta ANalysis. Version 8.00. Research Triangle Park, NC: Research Triangle Institute; 2001.

39. Zhang J, Yu KF. What's the relative risk? A method of correcting the odds ratio in cohort studies of common outcomes. JAMA 1998;280:1690-1691.

40. Doescher MP, Saver BG, Fiscella K, Franks P. [Abstract] Preventive Care: Does Continuity Count? North American Primary Care Research Group, 29th Annual Meeting. Halifax, Novia Scotia . 2001.

41. Blustein J, Hanson K, Shea S. Preventable hospitalizations and socioe conomic status. Health Aff (Millwood) 1998;17:177-189.

42. Lurie N, Ward NB, Shapiro MF, Gallego C, Vaghaiwalla R, Brook RH Termination of Medi-Cal benefits. A follow-up study one year later. N Engl J Med 1986;314:1266-1268.

43. Hjortdahl P. Continuity of care: general practitioners' knowledge about and sense of responsibility toward their patients. Fam Pract 1992;9:3-8. 